\title{
A Simulation Based Study on Increasing Production Capacity in a Crankshaft Line Considering Limited Budget and Space
}

\author{
Guan Wang $^{1} \cdot$ Shou Song ${ }^{1} \cdot$ Yang Woo Shin ${ }^{2} \cdot$ Dug Hee Moon ${ }^{1^{+}}$ \\ ${ }^{1}$ Department of Industrial and Systems Engineering, Changwon National University \\ ${ }^{2}$ Department of Statistics, Changwon National University
}

\section{예산과 공간 제약하에서 크랭크샤프트 생산라인의 생산능력 증대를 위한 시뮬레이션 기반의 연구}

\author{
왕 관 $^{1} \cdot$ 송 수 $^{1} \cdot$ 신양우 $^{2} \cdot$ 문덕희 $^{1}$ \\ ${ }^{1}$ 창원대학교 산업시스템공학과 / ${ }^{2}$ 창원 대학교 통계학과
}

In this paper, we discussed a problem for improving the throughput of a crankshaft manufacturing line in an automotive factory in which the budget for purchasing new machines and installing additional buffers is limited. We also considered the constraint of available space for both of machine and buffer. Although this problem seems like a kind of buffer allocation problem, it is different from buffer allocation problem because additional machines are also considered. Thus, it is not easy to calculate the throughput by mathematical model, and therefore simulation model was developed using ARENA ${ }^{\circledR}$ for estimating throughput. To determine the investment plan, a modified Arrow Assignment Rule under some constraints was suggested and it was applied to the real case.

Keywords: Production Capacity, Crankshaft Line, Limited Budget and Space, Modified Arrow Assignment Rule, Simulation

\section{Introduction}

The major components that make up an engine are popularly called the 5C's, namely, camshaft, crankshaft, cylinder block, cylinder head, and connecting rod. These major components are machined and assembled in their respective manufacturing sub-lines, and the completed components are transferred to the final engine assembly line. A final engine assembly line then consists of a series of assembly operations (Xu et al., 2012).
A crankshaft is the part of engine that changes the reciprocating linear piston motion into the rotation motion (see $<$ Figure 1>). To produce a crankshaft, various machining processes such as milling, drilling, turning, rolling, grinding, finishing, burnishing, and measuring processes are required. Although the process-flow of a crankshaft line is different among automotive factories, the typical layout concept is the flow-line having multiple parallel machines.

In general, the production lines of the components of an engine are highly automated. However, there are many reasons which could cause the breakdown in a process, and they

This research was partially supported by the Basic Research Program through the National Research Foundation of Korea(NRF), funded by the Ministry of Education(Grant Number NRF-2013R1A1A2058943 and NRF-2012R1A1B3004158).

† Corresponding author : Professor Dug Hee Moon, Department of Industrial and Systems Engineering, Changwon National University, Gyeongnam, 641-773, Korea, Tel :+82-55-213-3723, Fax :+82-55-266-4464, E-mail:dhmoon@changwon.ac.kr Received March 21, 2014; Revision Received April 21, 2014; Accepted May 29, 2014. 
are machine failure, changing tools, repair parts, set-up change, and so on. Some of these events occur with deterministic interval, but others occur with stochastic interval. Thus, buffer is installed between two successive operations to reduce the effects of starvation and blockage. The uncertainty of the breakdown influences the performance of the line, and it is also the main reason why most automotive factories implement a computer simulation to verify the layout design.

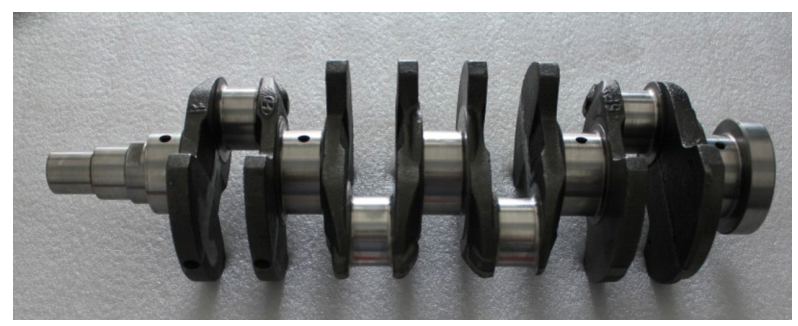

Figure 1. Example of crankshaft

There have been some researches using simulation that dealt with the design problem of a production line in an automotive factory. Since the whole system was too complicated, most of the studies in literature focused on the individual shop such as body shop, paint shop, engine shop, transmission shop and general assembly shop. Ulgen et al. (1994) discussed how to use of discrete-event simulation in the design and operation of body and paint shops, and they classified the use of simulation in the body shop into two aspects. The first classification was based on the stage of development of the system and the second was based on the nature of the problem investigated.

Jayaraman and Agarwal (1996) addressed a general concept when the simulation technique is applied to the engine plant, and Jayaraman and Gunal (1997) presented a simulation study in a testing area of an engine plant. The simulation studies regarding the engine block line have been suggested by Choi et al. (2002), Kumar and Houshyar (2002). In Moon et al. (2003), they considered the tool change times for specialized machines not equipping ATC (Automatic Tool Changer) in an engine block line. Dunbar III et al. (2009) described the simulation study of alternatives for transmission plant assembly line. Xu et al. (2010) compared three different types of layouts in automotive engine block lines and Moon et al. (2012) analyzed the effect of failure distribution in automotive engine line. Xu et al. (2012) presented a case study that integrates a simulation study with Analytic Hierarchy Process (AHP), and the integrated model was applied to the design of a transmission case line in a Korean automotive factory. The process-flow of the engine block line is similar to that of the crankshaft line or transmission case line.

The crankshaft line considered in this paper is an existing system operated by a Korean automotive company. The factory has a plan to increase the production capacity within the limited budget to meet the increasing demand, and thus, it is necessary to find where is the bottleneck for growing up throughput.

There have been some researches which deal how to find bottlenecks in manufacturing systems for improving the performances of systems (see Li and Meerkov, 2009; Lawrence and Buss, 1994; Kwon and Lim, 2013; Li et al., 2011). Most of the papers have focused on developing the detecting methods for bottlenecks.

Another area related to this paper is buffer allocation problem. There have been many researches dealing with the optimal buffer allocation problem. Powell (1994) studied the buffer allocation problem for unbalanced lines with three machines. Rules of thumb for the optimal sequential placement of buffer space were developed. Seong et al. (1995) used gradient search algorithm when the objective function is to maximize net profit. So (1997) presented a study on the optimal buffer allocation problem of minimizing the average work in process subject to a minimum required throughput and a constraint on the total buffer space. Gershwin and Schor (2000) suggested primal-dual problem considering optimal buffer space allocation in a serial line. A primal problem minimized total buffer space subject to a production rate constraint, and a dual problem maximized production rate subject to a total buffer space constraint. However, they did not consider the profit including cost. Huang et al. (2002) consider a flow shop-type production system and use a dynamic programming approach to maximize its production rate or minimized its work in process under a certain buffer allocation strategy. Chan and $\mathrm{Ng}$ (2002) compared buffer allocation strategies for maximized the production rate in serial production line. Amiri and Mohtashami (2012) presented a multi-objective formulation of the buffer allocation problem in a serial line in which unreliable machines, finite buffer and exponential service time were assumed. They developed a meta-model for estimating production rate based on discrete event simulation, and used genetic algorithm combined to line search method to solve the multi-objective model, maximizing production rate and minimizing buffer size, and determining the optimal (or near optimal) size of each buffer storage.

In this paper, we combine the simulation study for analysing manufacturing system and the bottleneck search method to determine investment plan considering the limitation of budget and available spaces for machines and buffers. The configuration of the crankshaft line and the mathematical model for optimizing investment plan under the limits of budget and available space are described in section 2. In section 3, 


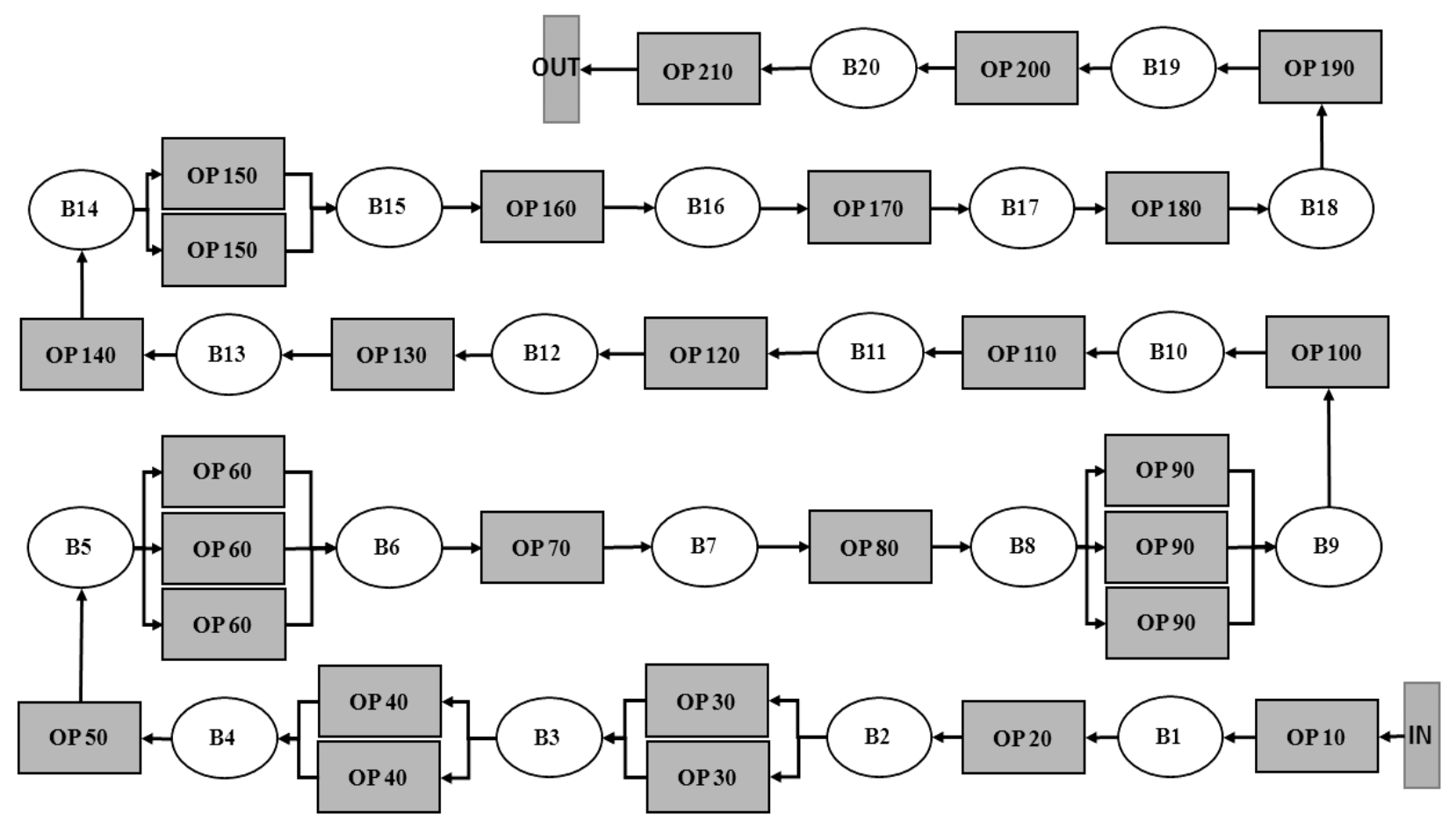

Figure 2. Processes of crankshaft manufacturing

Table 1. Descriptions of operations

\begin{tabular}{l|l|r|r|r|c}
\hline OP No & \multicolumn{1}{|c|}{ Processes } & $\begin{array}{c}\text { Number of } \\
\text { Machines(As-Is) }\end{array}$ & $\begin{array}{c}\text { Cycle Time } \\
(\text { sec. })\end{array}$ & $\begin{array}{c}\text { Machine Price } \\
(\$ 1,000)\end{array}$ & $\begin{array}{c}\text { Extra Available } \\
\text { Spaces }\end{array}$ \\
\hline OP-10 & Mass Centering & 1 & 50 & 1,180 & 0 \\
\hline OP-20 & Rear Turning & 1 & 46 & 230 & 0 \\
\hline OP-30 & Rough JR/Pin Milling & 2 & 140 & 952 & 1 \\
\hline OP-40 & Journal Grooving & 1 & 152 & 1,012 & 1 \\
\hline OP-50 & Pin Grooving and Milling & 3 & 195 & 962 & 0 \\
\hline OP-60 & Oil Hole Drilling & 1 & 48 & 120 & 2 \\
\hline OP-70 & Middle Washing & 1 & 51 & 1,010 & 0 \\
\hline OP-80 & Deep Rolling & 3 & 198 & 357 & 2 \\
\hline OP-90 & Re-centering and Hole Drilling & 1 & 48 & 270 & 1 \\
\hline OP-100 & Trust Turn and Rolling & 1 & 75 & 833 & 1 \\
\hline OP-110 & Journal Head Grinding & 1 & 52 & 1,190 & 1 \\
\hline OP-120 & Orbital Pin Grinding & 1 & 47 & 476 & 1 \\
\hline OP-130 & Front Angular Grinding & 1 & 54 & 476 & 1 \\
\hline OP-140 & Rear Angular Grinding & 2 & 160 & 417 & 2 \\
\hline OP-150 & CPS Hole Boring & 1 & 48 & 726 & 0 \\
\hline OP-160 & Final Balancing & 1 & 48 & 350 & 0 \\
\hline OP-170 & Deburring & 1 & 50 & 500 & 0 \\
\hline OP-180 & Lapping & 1 & 48 & 370 & 0 \\
\hline OP-190 & Final Washing & 1 & 51 & 390 & 0 \\
\hline OP-200 & Final Measuring & & & & 0 \\
\hline OP-210 & Sprocket Assembly & 150 & \\
\hline
\end{tabular}


simulation model is introduced and modified arrow assign rule for finding the best investment plan is suggested. The result of case study and its optimality are explained in section 4, and conclusion and further study are discussed in section 5 .

\section{Configurations and Objective}

The layout concept of the crankshaft line considered in this paper is a typical flow line as shown in $<$ Figure $2>$. In order to enhance the ease of machining or to reduce the risk of the breakdown of a line, some operations have two or three identical machines in parallel where a part chooses only one of machines and then it goes to the next operation after operation. Here, OP-30, OP-40, OP-60, OP-90 and OP-150 consist of multiple identical machines in parallel.

We assume that only one type of crankshaft is produced in this line, and the target of annual production quantity is 120,000 units. The annual working days are 261 days (21.75 days per month) and the working hours are 10 hours per day including the two hours of overtime.

\subsection{Configurations of the System}

- Operations and Cycle Times

Operations are designed considering the types of processes and the target tact time. If there are no failure, no tool change, no starvation and no blocking, the ideal target tack time is $261 \times 10 \times 3600 / 120,000=78.3$ seconds. $<$ Table $1>$ shows the details of operations including number of machines and operation cycle time. The longest average cycle time of an operation is 80 seconds at OP-150 when we assume that there are two machines in OP-150. Thus, this factory has to reduce the cycle times of some operations to meet the target production quantity.

At each operation, we assume that operation cycle time is deterministic because most of the machines are automated. Loading and unloading times are included in the operation cycle time. In some operations, there are multiple parallel machines for one operation because the tasks are complex, and it is difficult to separate them into two operations. Furthermore, an operation is composed of more than one process, for example there are 16 drilling and milling processes in OP-60, and 16 types of tools and their life cycles should be considered for modeling.

This factory has been built with some extra machine spaces and buffer spaces in some operations that give a possibility of making a plan to increase the throughput almost twice. $<$ Table $1>$ lists the existing number of machines, extra avail- able space, cycle time and machine price for each operation.

Table 2. Buffer capacity

\begin{tabular}{c|c|c}
\hline Buffer & Existing Capacity(As-Is) & Extra Capacity \\
\hline B1 & 20 & 10 \\
\hline B2 & 17 & 13 \\
\hline B3 & 2 & 0 \\
\hline B4 & 17 & 0 \\
\hline B5 & 20 & 10 \\
\hline B6 & 23 & 7 \\
\hline B7 & 15 & 15 \\
\hline B8 & 17 & 13 \\
\hline B9 & 17 & 0 \\
\hline B10 & 20 & 10 \\
\hline B11 & 34 & 10 \\
\hline B12 & 20 & 13 \\
\hline B13 & 17 & 10 \\
\hline B14 & 20 & 10 \\
\hline B15 & 20 & 0 \\
\hline B16 & 1 & 7 \\
\hline B17 & 23 & 14 \\
\hline B18 & 39 & 13 \\
\hline B19 & 16 & \\
\hline B20 & 17 & 0 \\
\hline Total & 375 & \\
\hline & & 15 \\
\hline
\end{tabular}

\section{- Buffers}

Various types of conveyor are used in the line for transportation and storage. A part should be loaded on a jig for transportation. Thus, the buffer capacity listed in $\langle$ Table 2>, means the maximum number of jigs to be installed in a conveyor between two successive operations. In B3, B4, B9, B11, $\mathrm{B} 16$ and $\mathrm{B} 18$, there is no available space for additional buffer. The price of additional one buffer (jig) is $\$ 200$, and the total investment cost for all additional buffers is $\$ 200 \times 155=$ $\$ 31,000$.

\section{- Down Times}

Two kinds of downtimes, machine failure and tool exchange are considered. The failure distributions are obtained from the historical data. The MTTF (Mean Time to Failure) and the MTTR (Mean Time to Repair) of the machine failure are listed in $\langle$ Table 3$\rangle$. The distribution functions of failure time and repair time are assumed to be exponential, and time dependent failure is assumed.

Tool change (or tip change) is assumed to be operation de- 
pendent failure. That is, tool change (or tip change) is required at every predetermined number of parts, and the number is defined as MCBF (Mean Count between Failures). If there are two or more tools in a machine, the MCBF's of tools are independent and may be different from each other. Most of machining centers equip ATC (Automatic Tool Changer) and many tools are inserted in tool magazine. $<$ Table $4>$ lists the tool types and MCBF of OP-90, where 14 tools are in ATC. Tool change time is the sum of the time for opening (and closing) door, the time for exchange tool and the time for in-line gauging. Opening and in-line gauging times are constant which are given as

- Time for opening and closing door $=0.33$ minutes,

- Time for in-line gauging $=3$ minutes

The time for exchange tools depends on the number of tools to be changed and it is given as

- Time for exchange tool $=0.67$ minutes $/$ tool .

Table 3. Input data of MTTF and MTTR

\begin{tabular}{c|c|c|c}
\hline OP No & $\begin{array}{c}\text { MTTF } \\
\text { (min.) }\end{array}$ & $\begin{array}{c}\text { MTTR } \\
\text { (min.) }\end{array}$ & $\begin{array}{c}\text { Down Time } \\
\text { Percentage }\end{array}$ \\
\hline OP-10 & $2,619.2$ & 42.9 & $1.61 \%$ \\
\hline OP-20 & $3,284.3$ & 43.3 & $1.30 \%$ \\
\hline OP-30 & $2,896.8$ & 61.1 & $2.07 \%$ \\
\hline OP-40 & $2,903.4$ & 54.4 & $1.84 \%$ \\
\hline OP-50 & $1,849.6$ & 51.9 & $2.73 \%$ \\
\hline OP-60 & $3,948.1$ & 45.0 & $1.13 \%$ \\
\hline OP-70 & $1,825.6$ & 75.9 & $3.99 \%$ \\
\hline OP-80 & $4,394.9$ & 41.9 & $0.95 \%$ \\
\hline OP-90 & $5,631.9$ & 72.6 & $1.27 \%$ \\
\hline OP-100 & $2,161.7$ & 56.7 & $2.56 \%$ \\
\hline OP-110 & $1,850.9$ & 50.6 & $2.66 \%$ \\
\hline OP-120 & $1,852.2$ & 49.3 & $2.59 \%$ \\
\hline OP-130 & $2,179.6$ & 38.8 & $1.75 \%$ \\
\hline OP-140 & $2,178.8$ & 39.6 & $1.79 \%$ \\
\hline OP-150 & $6,607.4$ & 47.8 & $0.72 \%$ \\
\hline OP-160 & $2,619.6$ & 42.5 & $1.60 \%$ \\
\hline OP-170 & $2,167.1$ & 51.3 & $2.31 \%$ \\
\hline OP-180 & $2,173.3$ & 45.1 & $2.03 \%$ \\
\hline OP-190 & $2,613.6$ & 48.5 & $1.82 \%$ \\
\hline OP-200 & $3,302.0$ & 25.6 & $0.77 \%$ \\
\hline OP-210 & $4,374.7$ & 62.1 & $1.40 \%$ \\
\hline
\end{tabular}

Since the tools having same MCBF should be changed at the same time, for example, T04 and T14 should be changed in every 200 cycles, the tool changing time is $0.33+0.67 \times 2+$ $3=4.67$ minutes. After producing 6,600 parts, six tools T04, T14, T01, T08, T09 and T02 should be changed at the same time, and the tool change time is $0.33+0.67 \times 6+3=7.35$ minutes.

\section{- Defectives}

Inspections for finding defectives are conducted in four operations OP-20, OP-50, OP-120 and OP-210, and the defect rates are $0.23 \%, 0.17 \%, 0.26 \%$ and $1.14 \%$, respectively. We assume that there is no repair or rework for the defectives.

Table 4. Input data of tool changes (OP-90)

\begin{tabular}{c|c|c}
\hline Tool No & Tool Type & MCBF \\
\hline T04 & TAP & 200 \\
\hline T14 & TAP & 200 \\
\hline T01 & DRILL & 330 \\
\hline T08 & REAMER & 330 \\
\hline T09 & DRILL & 330 \\
\hline T12 & END MILL & 450 \\
\hline T13 & DRILL & 500 \\
\hline T07 & DRILL & 500 \\
\hline T02 & INSERT TIP & 660 \\
\hline T06 & INSERT TIP & 990 \\
\hline T11 & INSERT TIP & 1,350 \\
\hline T03 & INSERT TIP & 1,800 \\
\hline T10 & TAP & 2,000 \\
\hline T05 & TAP & 2,000 \\
\hline
\end{tabular}

\subsection{Objective of Study}

The major concern of a company is to increase throughput within a limited budget. Generally, three types of strategies are usually applied to increase throughput, and they are buying additional machines, installing additional buffers and replacing tools with longer life cycles. However, in this paper we only consider the strategy of buying new machines and adding buffers. The total budget available is $\$ 1,050,000$ and the prices of new machines and additional buffer are addressed in section 2.1.

The mathematical model is defined as follows:

$$
\begin{aligned}
& \quad \max \Pi=\Phi\left(x_{1}, x_{2}, \cdots, x_{N}, y_{1}, y_{2}, \cdots, y_{N-1}\right) \\
& \text { s.t. } \sum_{i=1}^{N} C_{i} x_{i}+\sum_{i=1}^{N-1} D_{i} y_{i} \leq B, \\
& x_{i}: \text { integer and } 0 \leq x_{i} \leq f_{i} \text { for } i=1, \cdots, N, \\
& y_{i}: \text { integer and } 0 \leq y_{i} \leq g_{i} \text { for } i=1, \cdots, N-1,
\end{aligned}
$$


where $x_{i}$ and $f_{i}$ are the number of additional machines and its upper bound in operation $i$, respectively. $y_{i}$ and $g_{i}$ are the number of additional buffer and its upper bound between operations $i$ and $i+1$. Furthermore, $\Phi$ is the throughput of the system, $C_{i}$ is the price of machine $\mathrm{I}, D_{i}$ is the cost of additional one buffer and $\mathrm{B}$ is the total budget available.

\section{Solution Procedure}

\subsection{Simulation Model}

It is well known to be very difficult to derive analytical solution (i.e., approximation of queueing network) for the flow line with multiple unreliable machines, finite buffers, nonhomogeneous service times and the two types of failures. Note that both of time dependent failure and operation dependent failure are included in the model and the failure distribution functions are nonhomogeneous.

Simulation is known as useful tool for estimating the value of throughput $(\Phi)$, WIP (Work In Process), starving probabilities and blocking probabilities at once. Simulation models were developed with ARENA ${ }^{\circledR}$ (See Kelton et al. (2002)). To validate the simulation model developed, simulation run time was set to 146,410 minutes including 13,310 minutes of warm up time, and the number of replications was set to 100 . Then, the data gathering time was 133,100 minutes, and it was the 10 months in practice.

Table 5. Simulation result (As-Is)

\begin{tabular}{l|c|c|c|c}
\hline \multirow{2}{*}{ Real } & \multicolumn{2}{|c|}{ Simulation } & \multirow{2}{*}{ Error } \\
\cline { 3 - 4 } & & Mean & $95 \%$ C.I. & \\
\hline Throughput & 87,950 & 87,984 & \pm 171.7 & $0.04 \%$ \\
\hline
\end{tabular}

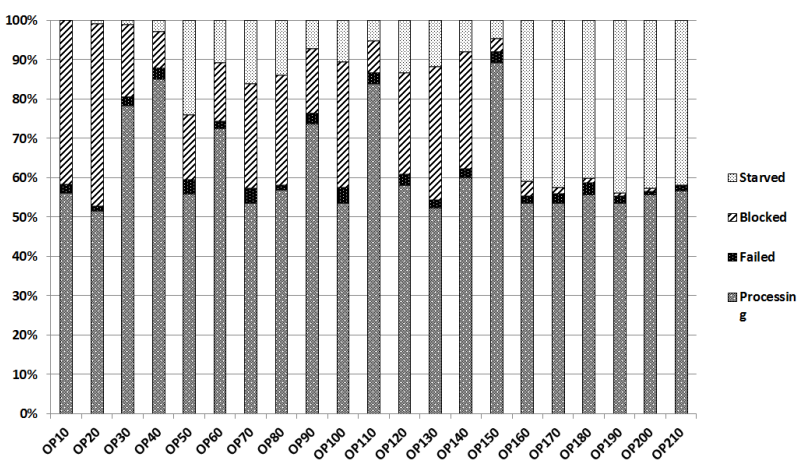

Figure 3. States of operations (As-Is)

The experimental results of 100 replications are presented in $\langle$ Table 5$\rangle$. The error obtained from simulation to the historical data in practice is $0.04 \%$, and we conclude that the simulation model is reasonably valid. The ratio of confidence interval to mean was $171.7 \div 87,984 \times 100=0.2 \%$. $<$ Figure $3>$ shows the portions of busy, idle (starvation), blockage and failure at each operation.

\subsection{Modified Arrow Assignment Rule}

The next step is to find which machine and buffer should be added to the existing system (As-Is) under the budget constraint. If there are no constraints of budget, the possible number of investment plans (combinations) is $\prod_{i=1}^{N}\left(f_{i}+1\right) \times$ $\prod_{i=1}^{N-1}\left(g_{i}+1\right)$ and that is about $3.61 \times 10^{18}$ in this problem. If the additional assignment strategy of buffer is assumed to be just zero or full capacity, the number of investment plans is reduced to $5.66 \times 10^{7}$.

To solve the integer problem, various meta-heuristic algorithms such as genetic algorithm (GA), tabu search, gradient search and etc. can be used. In order to use GA, the fitness value, namely throughput $(\Phi)$, should be estimated for each chromosome. When the number of chromosomes in the first generation is set to 100 , we need 100 simulation experiments. If the number of the different chromosomes in the second generation is reduced to 70 , we need additionally 70 simulation experiments. This process is repeated until the convergence is obtained. Furthermore, repair process is required for each crossover to consider the limited budget.

Similar situation is happened when various search algorithms are applied to this problem. Unfortunately, no metaheuristic algorithms guarantee the global optimality, and it is the reason that why we need faster heuristic algorithm.

There are some algorithms to find the bottleneck in a flow line, e.g., 'Arrow Assignment Rule' (Li and Meerkov, 2009), and 'Active Period Method' (Lawrence and Buss, 1994; Kwon and Lim, 2013) and a method using autoregressive moving average (ARMA) model (Li et al., 2011). In Arrow Assignment Rule, they considered a serial line having only one machine in each stage which has one type of time dependent failure, because they used mathematical approximation model for estimating throughput, WIP, blocking probabilities and starving probabilities.

In this paper, we adopt the concept of Arrow Assignment Rule for finding bottleneck and modify it with the considerations of limited budget and extra spaces for machines and buffers. We also introduce the concept of investment efficiency as in equation (6) to find the priority of investment.

Denote by $B L_{i}$ and $S T_{i}$ the blocking probability of machine $i\left(m_{i}\right)$ and the starving probability of $m_{i}$ in steady state, respectively and define the severity $\left(S_{i}\right)$ of $m_{i}$ by 


$$
\begin{aligned}
& S_{i}=\left|S T_{i+1}-B L_{i}\right|+\left|S T_{i}-B L_{i-1}\right|, \text { for } i=2, \cdots, N-1, \\
& S_{1}=\left|S T_{2}-B L_{1}\right| \\
& S_{N}=\left|S T_{N}-B L_{N-1}\right| .
\end{aligned}
$$

If $B L_{i} \geq S T_{i+1}$, assign the arrow pointing from $m_{i}$ to $m_{i+1}$. If $B L_{i}<S T_{i+1}$, assign the arrow pointing from $m_{i+1}$ to $m_{i}$. In case that there are multiple machines with no emanating arrows, the one with the largest severity $\left(S_{i}\right)$ is primary.

The following notations are used to explain the heuristic search rule. "Available" means that both of available space for machine (or buffer) and available investment cost are available. "Up" and "Down" means upstream and downstream, respectively. Efficiency is calculated by

$$
\text { Efficiency }=\frac{\text { Amount of throughput Icreased }}{\text { Investment } \cos t} .
$$

- TP : throughput,

- $B N$ : set of bottleneck machines,

- COM : machine candidate,

- $C O B$ : buffer candidate,

- e(COM) : efficiency of machine COM

- $e(C O B)$ : efficiency of buffer $C O B$

- $p_{-} B N \_m$ : primary bottleneck machine having the largest $S_{i}$ in $B N$,

- $s_{-} B N_{-} m$ : set of secondary bottleneck machines having smaller $S_{i}$ than $p_{-} B N \_m$ in $B N$,

- $s_{-} B N_{-} m_{-} a v l$ : subset of available machines in $s_{-} B N_{-} m$,

- $s_{-} B N_{-} m^{*}$ : machine having the largest $S_{i}$ in $s_{-} B N_{-} m_{-} a v l$,

- $p_{-} B N_{-} b$ : primary bottleneck buffer, where

$p_{-} B N \_b=\left\{\begin{array}{l}\text { Up buffer of } p_{-} B N_{-} m, \quad \text { if } S T_{i} \geq B L_{i} \\ \text { Down bufferof } p_{-} B N_{-} m, \text { if } S T_{i}<B L_{i}\end{array}\right.$

- $s_{-} B N_{-} b$ : set of secondary bottleneck buffer related to each machine $i$ in $s_{-} B N \_m$, where

$s_{-} B N_{-} b_{i}= \begin{cases}\text { Up buffer of } s_{-} B N_{-} m_{i}, & \text { if } S T_{i} \geq B L_{i} \\ \text { Down bufferof } s_{-} B N_{-} m_{i}, & \text { if } S T_{i}<B L_{i}\end{cases}$

- $S_{-} B N_{-} b \_a v l$ : subset of available buffers in $s_{-} B N_{-} b$,

- $s_{-} B N_{-} b^{*}$ : the buffer related to the machine having the largest $S_{i}$ in $s_{-} B N_{-} m$,

- $B N_{-}$Side $=\left\{\begin{array}{l}U p \text { side of } p_{-} B N_{-} m, \quad \text { if } S T_{i} \geq B L_{i} \\ \text { Down side of } p_{-} B N_{-} m, \text { if } S T_{i}<B L_{i}\end{array}\right.$

- BN_side_m : set of machines on $B N_{-}$side, which are not included in $B N$,

- BN_side_m_avl : subset of available machines in $B N_{-}$ side $m$,

- $B N \_$side_m* $m^{*}$ machine having the largest $S_{i}$ in $B N \_$side m_avl,

- BN_side $b:$ set of buffers on $B N_{-}$side which are neither $p_{-} B N_{-} b$ nor the buffers in $s_{-} B N_{-} b$,
- BN_side_b_avl: subset of available buffers in $B N_{-}$side_b,

- $B N_{-}$side_ $b^{*}$ : the buffer related to the machine having the largest severity in $B N$ side $m$,

- non $B N$ Side $=\left\{\begin{array}{l}U p \text { side of } p_{-} B N_{-} m, \quad \text { if } S T_{i} \geq B L_{i} \\ \text { Down side of } p_{-} B N_{-} m, \text { if } S T_{i}<B L_{i}\end{array}\right.$

- non $B N_{-}$side_m : set of machines on non $B N_{-}$side, which are not included in $B N$,

- non BN_side_m_avl : subset of available buffers in non $B N \_$side_m,

- non $B N_{-}$side $m^{*}$ : machine having the largest $S_{i}$ in non BN_side_m_avl,

- non BN_side_ $b$ : set of buffers on non $B N \_$side which are neither $p_{-} B N_{-} b$ nor buffers in $s_{-} B N_{-} b$,

- non BN_side $b$ avl : subset of available buffers in non $B N$ side_b,

- non $B N_{-}$side $b^{*}$ : the buffer related to the machine having the largest $S_{i}$ in non $B N_{-}$side_m,

$<$ Figure $4>$ explains the processes of search algorithm. The algorithm consists with a main routine and a subroutine $B$.

\section{Case Study and Validation}

\subsection{Case Study}

We carried out 100 replications of simulation run with the As-Is problem and the average throughput is 87,894 . The set of bottleneck machines $B N=\{\mathrm{OP}-40, \mathrm{OP}-60, \mathrm{OP}-110$, OP$150\}$ is obtained as shown in $<$ Figure $5>$. Among the operations in $B N, S_{i}$ of OP-150 is the largest $\left(S_{O P 150}=0.625\right)$, and thus $p B N m$ is OP-150 and $s B N m$ are OP-40, OP-60 and OP-110. Furthermore, $p_{-} B N_{-} b$ is B14, because $S T_{O P 150}$ $>B L_{O P 150}$, and $s_{-} B N_{-} b$ are $\mathrm{B} 4, \mathrm{~B} 6$ and $\mathrm{B} 11$ with respect to OP-40, OP-60 and OP-110. The upstream side of OP150 $\left(p \_B N \_m\right)$ is $B N$ side, and the downstream side of OP-150 is non $B N$ side.

In the first round, the machine candidate $(C O M)$ is OP-150, because there are two extra available spaces, and the price of machine is $\$ 417,000$ that is less than the total budget $\$ 1,050,000$. The buffer candidate $(C O B)$ is B14, because 10 extra buffers are allowed and the cost of extra buffers is $\$ 2,000$. Then, two simulation experiments are carried out for the two cases (adding a machine to OP-150 and adding 10 buffers to B14) independently, and new simulation results including throughput, WIP, starving probabilities and blocking probabilities are obtained. The throughput after adding one machine in OP-150 is 91,571 and the throughput in the case of increasing the buffer B14 to full is 88,714 . However, the investment 
efficiency of the former is 8.6 and it is lower than 356 of the later. Thus B14 is selected to increased to full in the first round. The remaining budget is $\$ 1,048,000$.

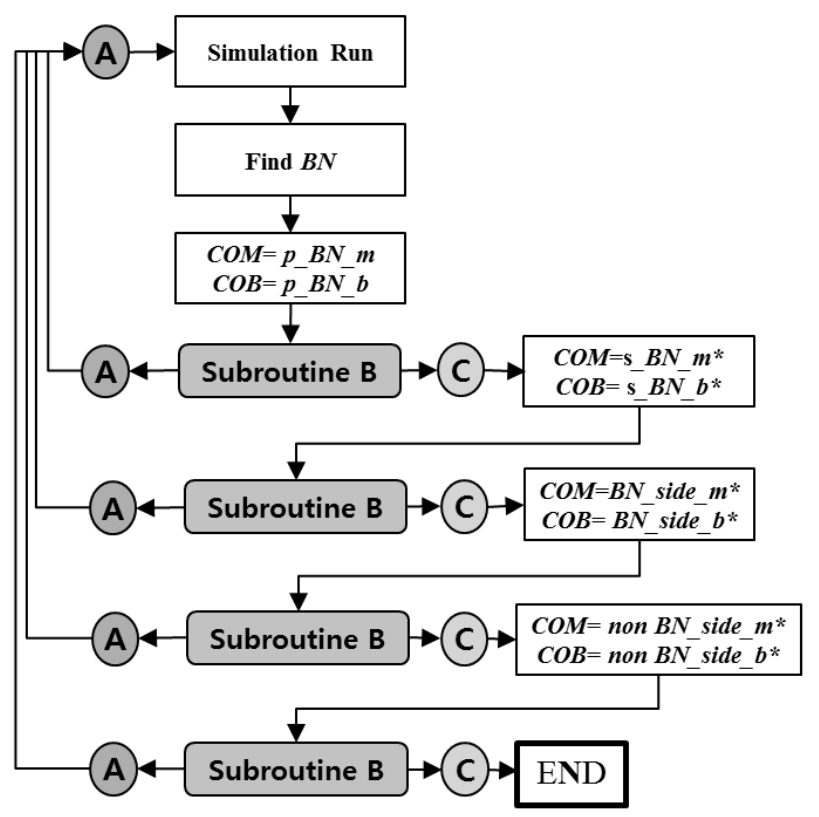

(a) Main routine

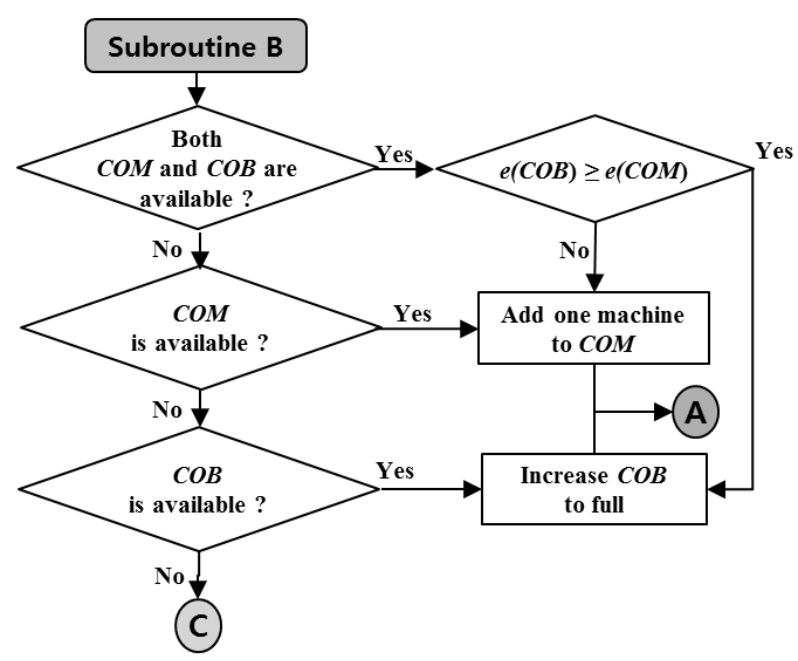

(b) Subroutine B

Figure 4. Flow chart of algorithm suggested

In the second round, the elements in $B N, p \_B N \_m$ and $p_{-} B N_{-} b$ are the same as the first round except that $C O B$ (B14) becomes unavailable. Thus, one new machine is added to OP-150. The new throughput is 91,687 and the increment is 2973 units (3.35\%). However, WIP decreases from 178.53 to 99.73 .

In the third round, three operations (OP-40, OP-90 and OP-110) are included in $B N$, and OP-110 becomes $p \_B N \_m$ and COM. But the machine price of OP-110 is higher than the remaining budget, $\$ 631,000$, it is unavailable. Thus, we increase the size of $C O B$ (B10) which is $p_{-} B N_{-} b$ to full, and the throughput obtained from new simulation is 91,953 , WIP is 98.49 , and the remaining budget is $\$ 629,000$.

In the fourth round, OP-110 is still $p B N m, \mathrm{~B} 10$ is $p_{-} B N_{-} b, \mathrm{OP}_{-} 40$ and OP-90 are elements of $s_{-} B N_{-} m$, and $s_{-} B N \_b$ contains B4 and B8. However, both of COM and $C O B$ are unavailable since the remaining budget is not enough for adding a machine in OP-110 and B10 is already full. For the secondary bottlenecks, machine prices of OP-40 $(\$ 1,012,000)$ is over the remaining budget and there is no available space in B4. Thus, they are not in $s_{-} B N_{-} m_{-} a v l$ and $s_{-} B N_{-} b \_a v l$., respectively and OP-90 becomes new COM and $\mathrm{B} 8$ becomes new $C O B$. After simulations, $e(C O B)$ is 9.77 and $e(C O M)$ is 5.51 . The next decision is to increase $\mathrm{B} 8$ to the full and then the new throughput is 92,121 and WIP is 99.63

In the fifth round, OP-110 becomes $p_{-} B N_{-} m$. OP-40 and OP-90 are included in $s_{-} B N_{-} m$. $s_{-} B N_{-} b$ contains B4 and B8. By the logic, an additional machine is added to OP-90. Then, the throughput is increased to 92,551 and WIP is 105.12 . The remaining budget is $\$ 269,400$.

\begin{tabular}{|c|c|c|c|c|c|c|c|c|}
\hline & OP10 & B1 & OP20 & B2 & OP30A & B3 & OP40A & B4 \\
\hline Starvation & $0.0 \%$ & & $0.8 \%$ & & $1.1 \%$ & & $3.0 \%$ & \\
\hline Blockage & $41.7 \%$ & & $46.4 \%$ & & $18.4 \%$ & & $9.1 \%$ & \\
\hline MC Price & & & & & & & $\$ 1,012$ & \\
\hline \multirow[t]{2}{*}{ Severity } & & & & & & & 0.303 & \\
\hline & OP50 & B5 & OP60A & B6 & OP70 & B7 & OP80 & B8 \\
\hline Starvation & $24.0 \%$ & & $10.8 \%$ & & $16.2 \%$ & & $13.9 \%$ & \\
\hline Blockage & $16.5 \%$ & & $14.8 \%$ & & $26.4 \%$ & & $28.0 \%$ & \\
\hline MC Price & & & $\$ 357$ & & & & & \\
\hline \multirow[t]{2}{*}{ Severity } & & & 0.071 & & & & & \\
\hline & OP90A & B9 & OP100 & B10 & OP110 & Bll & OP120 & B12 \\
\hline Starvation & $7.2 \%$ & & $10.6 \%$ & & $5.2 \%$ & & $13.4 \%$ & \\
\hline Blockage & $16.4 \%$ & & $31.8 \%$ & & $8.3 \%$ & & $25.7 \%$ & \\
\hline MC Price & & & & & $\$ 833$ & & & \\
\hline \multirow[t]{2}{*}{ Severity } & & & & & 0.318 & & & \\
\hline & OP130 & B 3 & OPl40 & 814 & OP1504 & B15 & OP160 & B]6 \\
\hline Starvation & $11.9 \%$ & & $8.0 \%$ & & $4.6 \%$ & & $40.8 \%$ & \\
\hline Blockage & $33.8 \%$ & & $29.8 \%$ & & $3.4 \%$ & & $3.9 \%$ & \\
\hline MC Price & & & & & $\$ 417$ & & & \\
\hline \multirow[t]{3}{*}{ Severity } & & & & & 0.625 & & & \\
\hline & & & & & & & & \\
\hline & OP170 & B17 & OP180 & B18 & OP190 & B19 & OP200 & B20 \\
\hline Starvation & $42.4 \%$ & & $40.2 \%$ & & $43.8 \%$ & & $42.6 \%$ & \\
\hline Blockage & $1.6 \%$ & & $1.0 \%$ & & $1.0 \%$ & & $0.9 \%$ & \\
\hline \multicolumn{9}{|l|}{ MC Price } \\
\hline \multicolumn{9}{|l|}{ Severity } \\
\hline \multirow{2}{*}{ 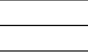 } & & & & & & & & \\
\hline & OP210 & & & & & & & \\
\hline Starvation & $41.8 \%$ & & & & & & & \\
\hline Blockage & $0.0 \%$ & & & & & & & \\
\hline \multirow{2}{*}{$\begin{array}{c}\text { MC Price } \\
\text { Severity }\end{array}$} & & & & & & & & \\
\hline & & & & & & & & \\
\hline
\end{tabular}

Figure 5. Candidates of bottleneck (As-Is)

The searching process is repeated until the remaining budget is consumed completely. In the sixth round, there is no available machine in $p_{-} B N_{-} m, s_{-} B N_{-} m, B N_{-}$side $m$, and non $B N_{-}$side_m, and no buffers are available in $p_{-} B N_{-} b$, $s_{-} B N_{-} b$. Thus, we should check up $B N_{-}$side first, and $\mathrm{B} 2$ is selected as a $C O B$ and we increase the capacity of B2 to 
maximum, because the severity of OP-20 is largest. Then the throughput becomes 92,611. Similarly, B6, B1, B5 and B7 are selected sequentially for $C O B$ in $B N \_$side and their capacities are increased to the upper bounds. After that, B19, $\mathrm{B} 17, \mathrm{~B} 15, \mathrm{~B} 12, \mathrm{~B} 13$ and $\mathrm{B} 20$ are selected in sequence for $C O B$ in $B N \_$side and their capacities are increased to the upper bounds. Then the final throughput increases to 94,017 and WIP is 136.59 . The total investment cost is $\$ 805,000$ and the remaining budget is $\$ 245,000$. The number of simulation experiments including As-Is analysis is 19 and the average simulation run time for each experiment is about 15 minutes.

Table 6. Summary of solution processes

\begin{tabular}{c|l|c|c|c}
\hline & \multicolumn{1}{|c|}{ Plan } & TP & WIP & $\begin{array}{l}\text { Remaining } \\
\text { Budget }\end{array}$ \\
\hline R0 & As-Is & 87,984 & 178.5 & $\$ 1,050,000$ \\
\hline R1 & B14 & 88,714 & 178.5 & $\$ 1,048,000$ \\
\hline R2 & B14 OP-150 & 91,687 & 99.7 & $\$ 631,000$ \\
\hline R3 & B14 OP-150 B10 & 91,953 & 98.5 & $\$ 629,000$ \\
\hline R4 & B14 OP-150 B10 B8 & 92,121 & 99.6 & $\$ 626,400$ \\
\hline R5 & $\begin{array}{l}\text { B14 OP-150 B10 B8 } \\
\text { OP-90 }\end{array}$ & 92,551 & 105.2 & $\$ 269,400$ \\
\hline $\begin{array}{c}\text { R6 } \\
\sim\end{array}$ & $\begin{array}{l}\text { B14 OP-150 B10 B8 } \\
\text { OP-90 B2 B6 B1 B5 } \\
\text { B7 B19 B17 B15 } \\
\text { B12 B13 B20 }\end{array}$ & 94,017 & 136.6 & $\$ 245,000$ \\
\hline
\end{tabular}

\subsection{Validation for Optimality}

To validate the solution procedure suggested, the best solution obtained from section 4.1 is compared with the feasible solutions obtained from all enumerations. However the number of all enumerations is too much big when we assume that the increment size of buffer is set to one. Thus, we inevitably assume that all available buffers are full, and search for the feasible investment plans for machines. Then the number of feasible plans is 30 . If we assume that the capacities of some buffers remain without increasing, then the number of feasible plans must be greater than 30 . $<$ Table $7>$ lists the simulation results for all enumerations with the decreasing order of throughput, and scenario 1 is the best and it is the same to the investment plan that we obtained from our heuristic method.

\section{Conclusions}

In this paper, we discussed a simulation study for improving the throughput of a crankshaft manufacturing line in an automotive factory, where there is the limitation of budget for purchasing new machines and installing additional buffers. In each operation and buffer, limited space is predetermined and it restricts the number of additional machines and buffers.

Although this problem seems like a buffer allocation problem, it is not easy to calculate the objective function (throughput) by mathematical model. Therefore, simulation model was developed using ARENA ${ }^{\circledR}$ and the values of throughput, starving probabilities, blocking probabilities and WIP were obtained by simulation experiments.

To determine the investment plan, we modified arrow assignment rule for considering parallel machines, the budget limitation and the space limitations of machines and buffers. Then, the best solution by the modified arrow assignment rule was compared to the subset of all enumerations (30 cases), and the two results were same. Although the modified arrow assignment rule does not guarantee the optimality, we obtained the best solution in the case study. Furthermore, the number of simulation experiments was reduced to 19 .

The limitation of this paper is that we inevitably assumed that the buffer increment is nothing or full. However, this assumption can be relaxed such that the buffer increment is set to one. In this case, we can use the algorithm suggested with the slight modification of buffer increment size, but the number of simulation experiments will be increased drastically. For further research, the objective function can be changed to minimizing cost which includes investment cost and WIP cost. In this case the target throughput becomes new constraint.

\section{References}

Amiri, M. and Mohtashami, A. (2012), Buffer Allocation in Unreliable Production Lines Based on Design of Experiments, Simulation, and Genetic Algorithm. International Journal of Advanced Manufacturing Technology, 62(1 4), 371-383.

Chan, F. T. S. and Ng, E. Y. H. (2002), Comparative Evaluations of Buffer Allocation Strategies in a Serial Production Line, International Journal of Advanced Manufacturing Technology, 19(11), 789800.

Choi, S. D., Kumar, A. R., and Houshyar, A. (2002), A Simulation Study of an Automotive Foundry Plant Manufacturing Engine Blocks, Proceedings of the 2002 Winter Simulation Conference, 1035-1040.

Dunbar, III, J. F., Liu, J. W. and Williams, E. D. (2009), Simulation of Alternatives for Transmission Plant Assembly Line, Proceedings of the Summer Computer Simulation Conference, 17-23.

Huang, M. G., Chang, P. L., and Chou, Y. C. (2002), Buffer Allocation in Flow-shop-type Production System with General Arrival and Service Patterns, Computers and Operations Research, 29(2), 103-121.

Jayaraman, A. and Agarwal A. (1996), Simulating an Engine Plant, 
Table 7. Simulation results (all enumerations)

\begin{tabular}{|c|c|c|c|c|c|c|c|}
\hline \multirow{2}{*}{ scenario } & \multirow{2}{*}{$\begin{array}{l}\text { Invest } \\
(\$ 1,000)\end{array}$} & \multirow{2}{*}{$\begin{array}{c}\text { Plan } \\
\text { (Machine) }\end{array}$} & \multicolumn{2}{|c|}{ Throughput } & \multicolumn{2}{|c|}{ Increment } & \multirow{2}{*}{ Efficiency $^{1)}$} \\
\hline & & & Mean & 95\% C.I. & Quantity & Percent & \\
\hline 1 & 805 & OP-90 OP-150 & 94,017 & \pm 149.2 & 6,033 & $6.86 \%$ & 7.49 \\
\hline 2 & 924 & OP-130 OP-150 & 93,613 & \pm 154.1 & 5,629 & $6.40 \%$ & 6.09 \\
\hline 3 & 924 & OP140 OP-150 & 93,555 & \pm 143.6 & 5,571 & $6.33 \%$ & 6.03 \\
\hline 4 & 718 & OP-100 OP-150 & 93,349 & \pm 132.9 & 5,365 & $6.10 \%$ & 7.47 \\
\hline 5 & 865 & OP-150 OP-150 & 93,334 & \pm 153.8 & 5,350 & $6.08 \%$ & 6.18 \\
\hline 6 & 805 & OP-60 OP-150 & 93,329 & \pm 146.4 & 5,345 & $6.07 \%$ & 6.64 \\
\hline 7 & 448 & OP-150 & 93,114 & \pm 139.3 & 5,130 & $5.83 \%$ & 11.45 \\
\hline 8 & 983 & OP-130 OP-140 & 91,769 & \pm 174.3 & 3,785 & $4.30 \%$ & 3.85 \\
\hline 9 & 864 & OP-60 OP-140 & 91,494 & \pm 140.8 & 3,510 & $3.99 \%$ & 4.06 \\
\hline 10 & 864 & OP-90 OP-140 & 91,492 & \pm 149.2 & 3,508 & $3.99 \%$ & 4.06 \\
\hline 11 & 777 & OP-100 OP-140 & 91,391 & \pm 138.7 & 3,407 & $3.87 \%$ & 4.38 \\
\hline 12 & 864 & OP-90 OP-130 & 91,330 & \pm 157.9 & 3,346 & $3.80 \%$ & 3.87 \\
\hline 13 & 1,043 & OP-40 & 91,245 & \pm 163.3 & 3,261 & $3.71 \%$ & 3.13 \\
\hline 14 & 864 & OP-60 OP-130 & 91,230 & \pm 155.3 & 3,246 & $3.69 \%$ & 3.76 \\
\hline 15 & 777 & OP-100 OP-130 & 91,222 & \pm 153.1 & 3,238 & $3.68 \%$ & 4.17 \\
\hline 16 & 507 & OP-130 & 91,175 & \pm 143.4 & 3,191 & $3.63 \%$ & 6.29 \\
\hline 17 & 1,015 & OP-60 OP-90 OP-100 & 91,159 & \pm 145.2 & 3,175 & $3.61 \%$ & 3.13 \\
\hline 18 & 1,015 & OP-90 OP-90 OP-100 & 91,137 & \pm 153.6 & 3,153 & $3.58 \%$ & 3.11 \\
\hline 19 & 658 & OP-90 OP-100 & 91,116 & \pm 139.8 & 3,132 & $3.56 \%$ & 4.76 \\
\hline 20 & 507 & OP-140 & 91,109 & \pm 138.6 & 3,125 & $3.55 \%$ & 6.16 \\
\hline 21 & 1,015 & OP-60 OP-60 OP-100 & 91,079 & \pm 151.7 & 3,095 & $3.52 \%$ & 3.05 \\
\hline 22 & 864 & OP-110 & 91,038 & \pm 118.7 & 3,054 & $3.47 \%$ & 3.53 \\
\hline 23 & 745 & OP-60 OP-60 & 90,760 & \pm 144.9 & 2,776 & $3.16 \%$ & 3.73 \\
\hline 24 & 658 & OP-60 OP-100 & 90,739 & \pm 135.2 & 2,755 & $3.13 \%$ & 4.19 \\
\hline 25 & 745 & OP-60 OP-90 & 90,735 & \pm 145.0 & 2,751 & $3.13 \%$ & 3.69 \\
\hline 26 & 388 & OP-60 & 90,694 & \pm 151.3 & 2,710 & $3.08 \%$ & 6.98 \\
\hline 27 & 745 & OP-90 OP-90 & 90,576 & \pm 128.8 & 2,592 & $2.95 \%$ & 3.48 \\
\hline 28 & 301 & OP-100 & 90,575 & \pm 130.7 & 2,591 & $2.94 \%$ & 8.61 \\
\hline 29 & 983 & OP-30 & 90,330 & \pm 112.6 & 2,346 & $2.67 \%$ & 2.39 \\
\hline 30 & 388 & OP-90 & 90,208 & \pm 126.4 & 2,224 & $2.53 \%$ & 5.73 \\
\hline
\end{tabular}

${ }^{1)}$ Calculated by Equation (6).

Manufacturing Engineering, 117(5), 60-68.

Jayaraman, A. and Gunal, A. K. (1997), Applications of Discrete Event Simulation in the Design of Automotive Power Train Manufacturing Systems, Proceedings of the 1997 Winter Simulation Conference, 758-764.

Kelton, W. D., Sadowski, R. P., and Sadowski, D. A. (2002), Simulation with ARENA 2nd Ed., McGraw Hill, New York, U.S.A.

Kwon, C. M. and Lim, S. G. (2013), Bottleneck Detection Based on Duration of Active Periods, Journal of the Korea Society for Simulation, 22(3), 35-41.
Lawrence, S. R. and Buss, A. H. (1994), Shifting Production Bottlenecks : Cause, Curse and Conundrums, Journal of production and Operations Management, 3(1), 21-37.

Li, J. and Meerkov, S. M. (2009), Production Systems Engineering, Springer Science+Business Media, New York, U.S.A.

Li, L., Chang, Q., Xiao, G. X., and Ambani, S. (2011), Throughput Bottleneck Prediction of Manufacturing Systems Using Time Series Analysis, Journal of Manufacturing Science and Engineering, 133(2), DOI:10.1115/1.4003786.

Moon, D. H., Sung, J. H., and Cho, H. I. (2003), A Case Study on the 
Verification of the Initial Layout of Engine Block Machining Line Using Simulation, Journal of Korea Society for Simulation, 12(3), 41-53.

Moon, D. H., Wang, G., and Shin, Y. W. (2012), Effects of Failure Distribution Considering Various Types of Layout Structure in Automotive Engine Shops, Journal of the Korean Institute of Industrial Engineers, 38(1), 7-16.

Powell, S. G. (1994), Buffer Allocation in Unbalanced Three-station Serial Lines, International Journal of Production Research, 32(9), 2201-2217.

Seong, D., Chang, S. Y., and Hong, Y. (1995), The Buffer Allocation with Linear Resource Constraints in a Continuous Flow Line, Journal of the Korean Institute of Industrial Engineers, 21(4), 541-553.

So, K. C. (1997), Optimal Buffer Allocation Strategy for Minimizing Work-in-process Inventory in Unpaced Production Lines, IIE Tran- sactions, 29(1), 81-88.

Gershwin, S. B. and Schor, J. E. (2000), Efficient Algorithms for Buffer Space Allocation, Analysis of Operational Research, 93(1 4), 117144.

Ulgen, O., Gunal, A. Grajo, E., and Shore, J. (1994), The Role of Simulation in Design and Operation of Body and Paint Shops in Vehicle Assembly Plants, Proceedings of the European Simulation Symposium, 124-128.

Xu, T., Moon, D. H., Shin, Y. W., and Jung, J. Y. (2010), An Effect Analysis of Layout Concepts on the Performances in Manufacturing Lines for Automotive Engine, Journal of the Korea Society for Simulation, 19(2), 107-118.

Xu, T., Moon, D. H., and Baek, S. G. (2012), A Simulation Study Integrated with Analytic Hierarchy Process (AHP) in an Automotive Manufacturing System, Simulation, 88(4), 450-463. 